\title{
Modelo de Eletrorresistividade Terrestre como Ferramenta de Ensino
}

\author{
Adriano Lopes Valente* (UFPA), Adriany Tiffany Moura Reis (UFPA), Nelson de Lima Ribeiro Filho (UFPA), Me. Alberto \\ Leandro de Melo (UFPA), Dr. ${ }^{\text {a }}$ Carolina Barros da Silva (UFPA)
}

Copyright 2016, SBGf - Sociedade Brasileira de Geofísica

Este texto foi preparado para a apresentação no VII Simpósio Brasileiro de Geofísica, Ouro Preto, 25 a 27 de outubro de 2016. Seu conteúdo foi revisado pelo Comitê Técnico do VII SimBGf, mas não necessariamente representa a opinião da SBGf ou de seus associados. $\dot{E}$ proibida a reprodução total ou parcial deste material para propósitos comerciais sem prévia autorização da SBGf.

\section{Resumo}

In this article, we propose the using of a small geophysical model as a teaching tool and application of subjects which are taught in elementary and high school. Therefore, basic subjects were used, like process of sedimentation and soil formation, weathering and electric phenomena, which belong to National Curriculum Standards of the Third and Fourth Cycles of the Elementary School and the ENEM's Reference Parameters. Moreover, we constructed a small model, in which we simulated an electric acquisition to investigate the subsurface of the supposed geological environment. Then, we established a relationship between subjects teaching in the school and the world around, beyond to be a manner of disseminate the geophysical acting.

\section{Introdução}

O presente artigo visa elucidar as etapas de construção de um modelo, em escala reduzida, a fim de que este seja uma ferramenta de ensino de conteúdos das áreas de Geografia e Ciências Naturais referentes aos processos geológicos que levaram a formação das camadas da subsuperfície terrestre e seu relevo; e que, além disso, permita o estudo das propriedades elétricas das mesmas. Tais conteúdos foram definidos pela Secretaria de Educação e pelo Ministério da Educação como pertencentes aos Parâmetros Curriculares Nacionais do Terceiro e Quarto Ciclos do Ensino Fundamental e à Matriz de Referência do ENEM, respectivamente.

O modelo foi desenvolvido e construído no Laboratório de modelagem da Faculdade de Geofísica da Universidade Federal do Pará, com o apoio da Sociedade Brasileira de Geofísica (SBGF), a fim de integrar a exposição "O que é Geofísica?" - projeto de extensão que percorre feiras, congressos e simpósios de cunho nacional e internacional - buscando apresentar aos alunos do ensino fundamental, médio e técnico, uma nova forma de relacionar as leis físicas aos fenômenos naturais já estudados, além de difundir as áreas de atuação da Geofísica.

\section{Metodologia de Ensino}

O modelo de eletrorresistividade terrestre permite aos alunos uma melhor compreensão de assuntos abordados em sala de aula, podendo ser incluído na metodologia de ensino em três relevantes contextos: os processos de deposição sedimentar e formação do solo; o processo de intemperismo; e as relações físicas da eletricidade e circuitos elétricos.

\section{Intemperismo e Formação do Solo}

Há milhões de anos, as camadas de rochas na superfície da Terra estão expostas a variações climáticas e de temperatura, ações da chuva e do vento, da água de rios e correntes marinhas, sofrendo sucessivos desgastes. $O$ intemperismo, como é denominado este processo, com o decorrer do tempo, promove a fragmentação das rochas pré-existentes por meio de transformações físicas e químicas, gerando novos sedimentos que farão parte do processo de deposição. Este processo pode ocorrer em diferentes tipos de ambientes geológicos, tais como, os ambientes terrestres, marinho, lagunar, de transição etc. Desta forma, lentamente ocorreu a formação do solo, que enfrenta um processo contínuo de remodelação.

Tais conteúdos estão atrelados à formação das camadas da subsuperfície da Terra e seu relevo, os quais são ministrados ao longo do Terceiro e Quarto Ciclos do Ensino Fundamental de acordo com as determinações da Secretaria de Educação.

Baseado nesses conteúdos, e a fim de aplica-los em sala de aula, desenvolvemos e construímos um modelo em escala reduzida para simular um ambiente geológico. Neste ambiente, a princípio, ocorreu um evento de subsidência, gerando um espaço de acomodação propício à deposição de sedimentos. Assim, esta sedimentação deu origem a camadas dispostas de forma plano-paralela, como ilustra a figura abaixo.

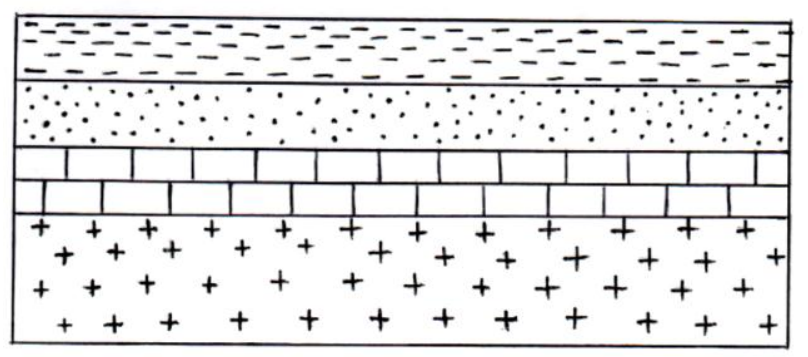

Figura 1: Camadas Plano Paralelas (Fonte: dos autores)

Posteriormente, ocorreram processos envolvendo esforços tectônicos, os quais levaram ao desenvolvimento de falhas normais. Estas falhas desenvolvem-se a partir de esforços distensivos e correspondem ao deslizamento do bloco rochoso localizado acima do plano de falha em relação ao bloco 
abaixo do plano de falha. A situação descrita está ilustrada na figura 2 a seguir.

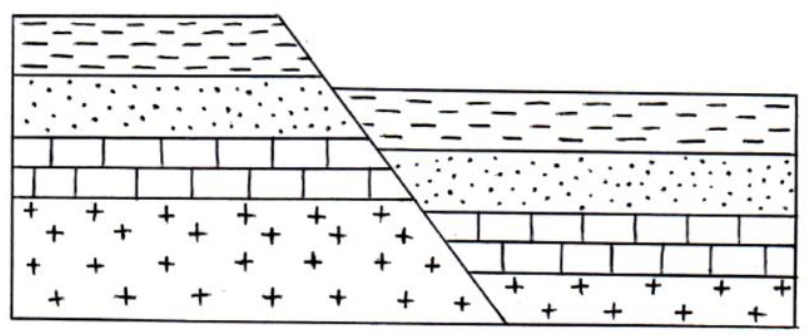

Figura 2: Falha Normal (Fonte: dos autores)

O evento seguinte corresponde à intrusão magmática ao longo do plano de falha gerando diques e soleiras. Estas intrusões tornaram-se zonas mineralizadas. Tal processo de mineralização pode ter sido anterior, concomitante ou posterior à deposição de uma camada sedimentar mais recente.

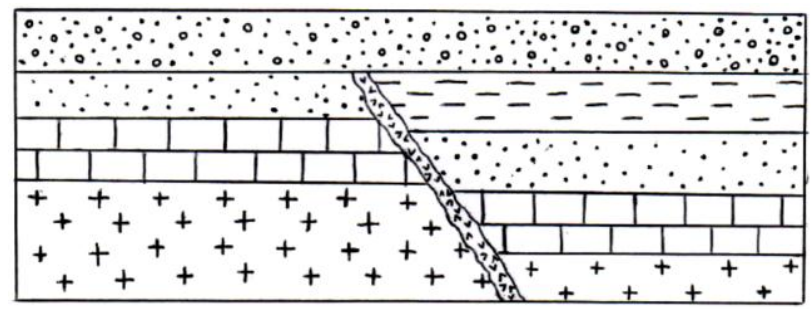

Figura 3: Zona Mineralizada (Fonte: dos autores)

\section{Eletricidade e Circuitos Elétricos}

De acordo com a matriz de referência do ENEM, estabelecida pelo Ministério da Educação, alunos do ensino médio, em especial os que estão cursando o terceiro ano, devem dominar os conteúdos associados a fenômenos elétricos. Tais conteúdos abordam conceitos a respeito de carga elétrica, corrente elétrica e lei de Coulomb; campo elétrico, potencial elétrico e representação das linhas de campo; superfícies equipotenciais; poder das pontas; blindagem; capacitor elétrico e Efeito Joule; Lei de Ohm; resistência elétrica e resistividade; relações entre grandezas elétricas: tensão, corrente, potência e energia; circuitos elétricos simples; corrente contínua e corrente alternada; medidores elétricos; representação gráfica de circuitos; símbolos convencionais; potência e consumo de energia em dispositivos elétricos.

Assim, a fim de aplicar os conteúdos ministrados em sala, este modelo de eletrorresistividade terrestre, também pode ser utilizado como uma ferramenta de ensino, visto que, numa escala reduzida, ele representa um método indireto de investigação da subsuperfície através da injeção de correntes elétricas.

Neste método, uma corrente elétrica alternada de baixa frequência - inferior a $1 \mathrm{~Hz}$ - é injetada através de contatos diretos com solo feitos por eletrodos metálicos, denominados $\mathrm{A}$ e $\mathrm{B}$, e a diferença de potencial também é observada por meio de contato direto com o solo através de eletrodos denominados $M$ e $N$. Comumente denomina-se A e B por eletrodos de corrente, e $\mathrm{M}$ e $\mathrm{N}$ por eletrodos de potencial. Como o objetivo deste método é investigar a subsuperfície a partir da resistividade dos diferentes materiais que a constituem, tendo conhecimento da corrente que está sendo injetada no terreno, medida por meio de um amperímetro ou um multímetro, e da diferença de potencial, medida por meio de um voltímetro ou um multímetro, a uma distância $r$ da fonte, utilizamos a seguinte equação para calcular a resistividade do terreno:

$$
\rho=\frac{\Delta V}{I} k
$$

(Equação 1)

Onde $k$ é o fator geométrico, cujo valor depende das posições de injeção de corrente e de medida de potencial.

Entretanto, tanto o ambiente geológico real, quanto o simulado por nosso modelo, não são homogêneos. Logo, o valor da resistividade sofrerá variações de acordo com o fator geométrico e com a posição do arranjo de medida. Desta forma, as medidas de resistividade obtidas representam uma resistividade aparente $\left(\rho_{a}\right)$, que consiste em uma expressão da resistividade que o meio teria caso fosse homogêneo, podendo ser maior, igual ou menor que os valores reais de resistividade do meio. No entanto, apesar de a resistividade aparente não ser a real resistividade do meio, baixos valores de resistividade aparente sugerem a presença de corpos que são bons condutores de eletricidade e vice-versa.

Como o modelo construído apresenta variações laterais de resistividade, devido à presença de falhas, diques e soleiras, o sistema de levantamento mais indicado é a Perfilagem Elétrica ou Caminhamento Elétrico. Este levantamento "consiste no deslocamento lateral conjunto dos quatro eletrodos sem modificar as suas distâncias relativas". (LUIZ; SILVA, 1983, p. 151). Nesse tipo de levantamento, a profundidade de investigação permanece aproximadamente constante em todos os pontos de medida, visto que a distância entre os eletrodos de corrente permanece fixa.

O arranjo de medida utilizado no Caminhamento elétrico foi o arranjo Wenner, o qual é composto por quatro eletrodos equidistantes, dispostos linearmente e simetricamente em relação ao centro do arranjo, representado pelo ponto $P$. Dessa forma, os eletrodos de potencial localizam-se entre os dois eletros de corrente. Tal geometria está ilustrada na figura 4 a seguir:

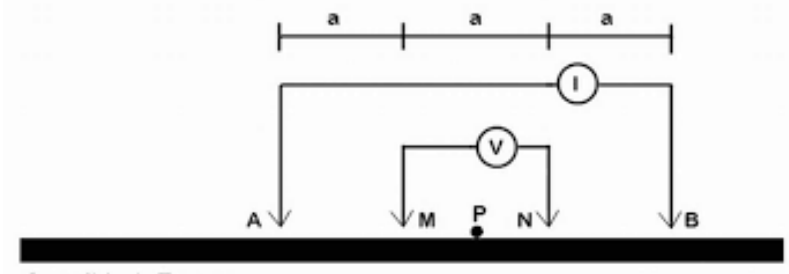

Superficie do Terreno

Figura 4: Arranjo Wenner (Fonte: Werglang et al. 2012)

Para este arranjo, o fator geométrico $k$ é dado por:

$$
k=2 \pi a
$$

onde a é o espaçamento entre os eletrodos do arranjo.

Com base nesse fator geométrico, a diferença de potencial pode ser obtida a partir da equação 3 


$$
\Delta V=\frac{\rho I}{2 \pi a} \quad \text { (Equação 3) }
$$

e o valor medido de resistividade aparente pode ser expresso por:

$$
\rho_{a}=\frac{\Delta V}{I} 2 \pi a \quad \text { (Equação 4) }
$$

Dessa forma, ss medidas de resistividade obtidas através do arranjo Wenner, são atribuídas ao centro do arranjo.

Como o modelo construído possui zonas mineralizadas na forma de diques e soleiras, e estas regiões registram baixos valores de resistividade, é possível introduzir a estimativa de um perfil elétrico teórico obtido por meio de caminhamento utilizando 0 arranjo Wenner. Sua representação é dada pela figura 5 .
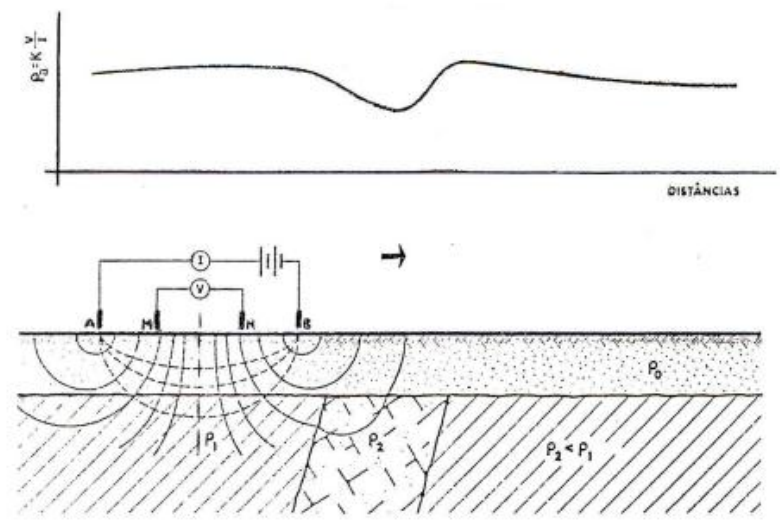

Figura 5: Pefil de caminhamento elétrico com arranjo Wenner (Fonte: Apostila Geologia de Engenharia da Faculdade de Engenharia da Universidade do Porto, p. 10)

Desta maneira é possível estabelecer uma relação entre os fenômenos físicos e o objeto de investigação, que pode ser uma zona mineralizada, um aquífero, pluma de contaminação etc.

\section{Metodologia de Construção}

O modelo geológico idealizado era formado por camadas plano-paralelas que compunham um ritmito formado a partir de variações do nível do mar associadas a movimentos eustáticos, os quais podem ter sido provocados por períodos de glaciação e deglaciação, ou variações do volume de bacias oceânicas, ou mudanças de temperatura a nível global, ou mesmo períodos de chuva excessivos. Para representar os períodos associados a eventos de maior energia, foram utilizados sedimentos de granulometria grossa, como seixo, areia grossa e média, já para representar os períodos associados a eventos de menor energia, foram utilizados sedimentos de granulometria fina, como silte e argila, pois, devido ao aumento do nível do mar, o ambiente fica mais calmo, permitindo a deposição de sedimentos mais finos. Além disso, tais camadas seriam atravessadas por falhas normais, através das quais ocorreu um processo de intrusão magmática, gerando uma zona mineralizada, a qual foi representada por meio de sedimentos cobreados através de um processo de eletrólise.

Para tanto, o processo de construção se deu em uma caixa de madeira com $1 \mathrm{~m}$ (um metro) de comprimento, $40 \mathrm{~cm}$ (quarenta centímetros de altura) e $5 \mathrm{~cm}$ (cinco centímetros de largura). Esta caixa foi impermeabilizada e preenchida com água, visto que o processo de sedimentação se dá em meio aquoso. Os sedimentos foram despejados manualmente no tanque, de modo que eles pudessem compor cada uma das camadas, de acordo com o modelo proposto. Este procedimento é ilustrado na figura 6 a seguir:

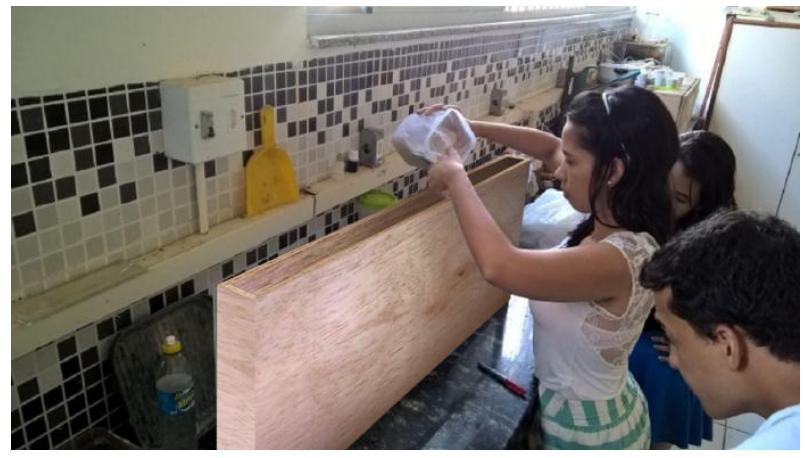

Figura 6: Processo de sedimentação (Fonte: dos autores)

Finalizando a etapa de deposição dos sedimentos, iniciou-se o processo de desidratação das camadas, com o auxilio de mangueiras localizadas nas laterais do tanque. Esta etapa tem a finalidade de auxiliar no processo de compactação das camadas, juntamente com o peso das camadas sobrepostas.

$\mathrm{Na}$ etapa seguinte, foram feitos dois cortes na caixa de madeira atravessando as camadas e deslocamos os blocos gerados um em relação ao outro a fim de simular o deslocamento provocado por falhas normais.

Feito isso, retirou-se uma das tampas laterais da caixa e removemos parte dos sedimentos localizados próximo aos contatos das falhas com as camadas e entre as camadas, para que então pudéssemos introduzir os sedimentos cobreados, a fim de que estes pudessem representar os diques e soleiras formados por meio da intrusão ígnea. Além disso, foi realizado o cobreamento dos sedimentos das próprias camadas. Por fim, transferimos o modelo para um tanque de acrílico, para que este pudesse ser mais bem visualizado, como ilustrado abaixo.

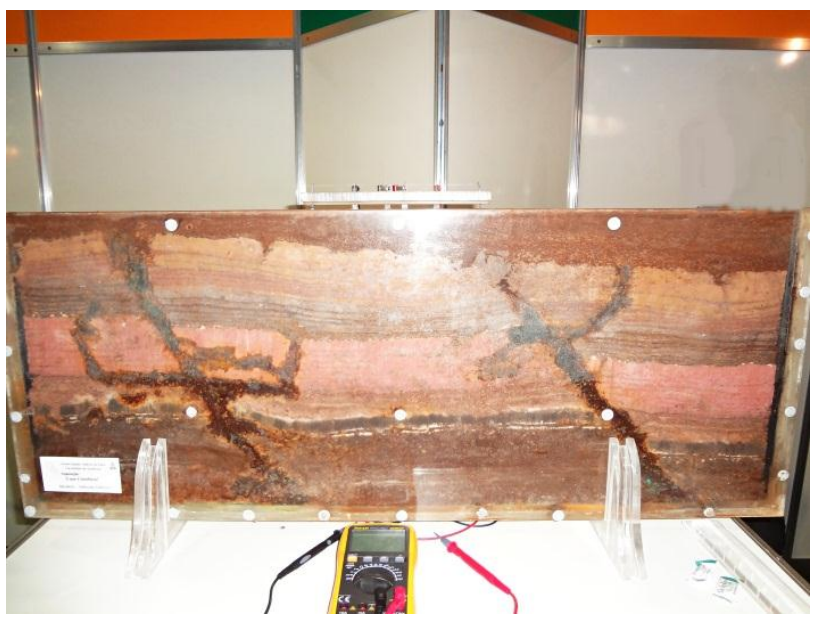

Figura 7: Modelo de Eletrorresistividade Terrestre (Fonte: dos autores) 
Para a realização do processo de medida, foi construído um suporte de acrílico, no qual foram fixados quatro eletrodos igualmente espaçados entre si e simétricos em relação a um ponto central. Os dois eletrodos fixados nas extremidades do suporte têm por finalidade a injeção de uma corrente alternada de baixa frequência, que são os eletrodos $\mathrm{A}$ e $\mathrm{B}$, fornecida por meio de uma bateria; já os dois eletrodos centrais têm por finalidade medir a diferença de potencial, que são os eletrodos M e N. Esta medição foi realizada através de um multímetro. Todos os eletrodos foram fincados no modelo a fim de estabelecer um contato que permitisse a realização das medidas. Após a realização da medida num determinado ponto, todo o conjunto de eletrodos era deslocado para o ponto seguinte por meio do suporte. Desta maneira, era possível simular um levantamento ao longo de todo o modelo.

Como prevíamos, nos pontos de medida localizados próximos às zonas mineralizadas, era possível observar uma diminuição do valor da diferença de potencial medida, indicando zonas de baixa resistividade, as quais estão associadas às zonas mineralizadas.

\section{Discussão e Conclusões}

Tendo em vista os aspectos apresentados, a implementação de modelos que simulem situações geofísicas como uma ferramenta de ensino lúdica encaixa-se perfeitamente no contexto escolar, tanto para o ensino fundamental, quanto para o ensino médio, realizando uma extensão do que é ensinado em sala de aula, e incentivando um instinto investigativo no aluno, que sem dúvida irá culminar em interações sócioeducacionais mais efetivas, buscando desenvolver novas ferramentas para aplicação em situações cotidianas. Além disso, a inserção de tais modelos na metodologia de ensino torna-se uma maneira de introduzir a comunidade escolar as áreas de atuação da Geofísica.

\section{Agradecimentos}

Os autores agradecem à Sociedade Brasileira de Geofísica - SBGF, pelo apoio à construção dos modelos no Laboratório de Modelagem, à Universidade Federal do Pará, à Faculdade de Geofísica, ao Programa de Educação Tutorial - PET e à Kleberson Aguiar Moura pelo auxílio na formatação.

\section{Referências}

ALENCOÃO, Ana. FERREIRA, Cândida. VASCONCELOS, Clara. O Recurso à Modelação no Ensino das Ciências: Um Estudo com Modelos Geológicos. Revista Ciências \& Educação. V. 21. № 1. P. 31 - 48. Bauru, 2015. Disponível em: $<$ http://www.scielo.br/pdf/ciedu/v21n1/1516-7313-ciedu21-01-0031.pdf>. Acesso em 25 de Janeiro de 2016.

BRAGA, Antonio Celso de Oliveira. Métodos Geoelétricos Aplicados nos Estudos de Captação e Contaminação das Águas Subterrâneas. Nota de aula. Universidade Estadual Paulista Julio de Mesquita Filho, Instituto de Geociências e Ciências Exatas. Rio Claro, 2007.
BRASIL. Ministério da Educação. Matriz de Referência do ENEM. Brasília: MEC/INEP, 2011.

BRASIL. Secretaria de Educação Fundamental. Parâmetros curriculares nacionais: terceiro e quarto ciclos do ensino fundamental: introdução aos parâmetros curriculares nacionais. Brasília: MEC/SEF, 1998.

CARNEIRO, Celso Dal Ré; PIRANHA, Joseli Maria. O Ensino de Geologia como Instrumento Formador de uma Cultura de Sustentabilidade. Revista Brasileira de Geociências. V. 39. № 1. 2009. Artigo digital disponível em:

<http://ppegeo.igc.usp.br/pdf/rbg/v39n1/v39n1a10.pdf>. Acesso em 26 de Janeiro de 2016.

LUIZ, José Gouvêa; SILVA, Lúcia Maria da Costa e. Curso de Geofísica de Prospecção. 1. ed. UFPA, 1983. p. $141-175$.

PRESS; SIEVER; GROTZINGER; JORDAN. Para Entender a Terra. 4. ed. Bookman, 2006. p. 171 - 207.

WERGLAN, R. B. et al; Análise da Inserção da Teoria Sóciointeracionista em Atividades de Laboratório de Física Básica em um curso de Geofísica. Caderno Brasileiro de Ensino de Física, v. 29, n. 2, p.260. Agosto, 2012. 